\title{
COMMENTARY
}

\section{Navigating the Unchartered Waters in the Time of COVID-19}

\author{
Gayle Brazeau, PhD, ${ }^{\mathrm{a}, \mathrm{b}}$ Frank Romanelli, PharmD, $\mathrm{MPH}^{\mathrm{c}, \mathrm{d}}$ \\ ${ }^{a}$ Marshall University, Huntington, West Virginia \\ ${ }^{\mathrm{b}}$ Editor, American Journal of Pharmaceutical Education, Arlington, Virginia \\ ${ }^{\mathrm{c}}$ University of Kentucky, Lexington, Kentucky \\ d Executive Associate Editor, American Journal of Pharmaceutical Education, Arlington, Virginia \\ Submitted March 18, 2020; accepted March 18, 2020; published March 2020.
}

Many of us could have never envisioned, even in our wildest dreams, the current situation we are facing across the Academy. The novel coronavirus 2019 (COVID-19) pandemic has left an indelible mark on our lives forever. We all feel and see the stress and anxiety in our students, faculty, staff, preceptors, and alumni as our programs navigate the unchartered waters of empty classrooms, alternative educational formats and platforms, teleworking situations for faculty and staff and stressed clinical practice sites. The angst is probably most tangible within the realm of experiential education where contact precautions have led to ever-increasing reductions in the availability of introductory and advanced pharmacy practice experiences. Further complicating an already tense situation is the fact that the pandemic is coming at one of the busiest periods in the academic calendar when colleges and schools are preparing for commencement exercises and other key end-of-year functions and activities.

Despite these challenges, we know that our collective pharmacy academy will be resilient as we have a long and successful record of being creative problem solvers as evidenced by the quality of papers published in the Journal. We, as an Academy, have time and time again, shown how programs across the nation, public versus private, new versus established, large versus small, always come together to enhance the quality of our educational programs, advance student professional development and leadership, and promote the success of our faculty colleagues. COVID-19 is a novel challenge, but pharmacy educators and our students have always shown that they will find a way to succeed if we embrace the following five considerations to help us collectively reduce the anxiety that we all may be feeling during this time.

Understanding, empathy and patience must be the foundation of our individual and collective actions. There will be new challenges in our educational endeavors and interactions with each other that must be based upon seeking understanding and demonstrating empathy as we become accustomed to evolving ways of teaching, learning, and assessment in the weeks to come. We should be patient with ourselves and with others given that each of us are dealing with circumstances with our families, friends, and communities. Small or large acts of kindness will go a long way to build a sense of community. We have repeatedly seen that pharmacy educators, student pharmacists, residents, and graduate students in our programs have always shown generosity in the greatest gift that one can give to another, the gift of time and efforts. We know this current situation will be no different. Finally, let us show gratitude and appreciation to others and to ourselves as we learn and grow personally and professionally during this time.

In the coming months we should focus on finding opportunity and purpose among the adversity and in some instances tragedy that may surround us. The pandemic may change our lives in lasting ways both small and large. The impact of our collective colleges and schools mobilizing over a short period of time to deliver professional and graduate curricula online is significant. As will be the effects of shifting our academic workforce away from the brick and mortar of our colleges into personal at-home working spaces. As scientists and scholars, the pandemic should serve as a reminder of the powerful and often inexplicable world we live in and our goal to better understand it.
Corresponding Author: Gayle A. Brazeau, Marshall University, School of Pharmacy, One John Marshall Dr., Huntington, WV 25755. Tel: 304-696-7390. Fax: 304-6967309. Email: brazeau@marshall.edu 